\title{
Family Empowerment Model Based on Belief and Health-Related Quality of Life among Housewives With HIV/AIDS
}

\author{
Nursalam Nursalam ${ }^{1}$, Ferry Efendi ${ }^{1}, \operatorname{Rr}$ Dian Tristiana ${ }^{1}$, Misutarno Misutarno ${ }^{2}$, Dluha Maf'ula ${ }^{1}$, Diah \\ Priyantini ${ }^{1}$ \\ ${ }^{1}$ Faculty of Nursing, Universitas Airlangga, Surabaya, Indonesia \\ ${ }^{2}$ RSUD Dr. Soetomo, Surabaya, Indonesia
}

Article History:

Submitted: 06.03.2020

ABSTRACT

The trend of Human Immunodeficiency Virus/ Acquired Immunodeficiency Syndrome (HIV/AIDS) prevalence in Indonesia has increased significantly. This study was aimed to develop family empowerment model based on belief and analyze the effects of health-related quality of life (HRQL) in patients infected by HIVIAIDS. Mixed methods design with the first stage using quantitative research with cross sectional approach. A total 135 respondents with HIV/AIDS were determined from purposive sampling. For developing the model, we conducted focus group and expert discussion to make the model and the intervention tool for the second stage. We analyzed the collected data using Structural Equation Model Partial Least Squares (SEM-PLS) test. The outer loading value measured the sub-variable validity value of its latent variable, where the outer loading is valid if the value is $>0.4$. Based on the research results, nine indicators were invalid (outer loading value $\leq 0.4$ ), and the indicator must be removed from the model.
Revised: 10.04 .2020

Accepted: 11.05 .2020

Evaluation of inner models was used to test the research hypotheses. The research hypothesis can be accepted if the value of T count $>T$ table. The health services, patient factors, family factors and empowerment have a significant influence between some of these factors on HQRL ( $T$ >1.96). The development of a family empowerment model based on belief has a good effect in healthrelated quality of life among women with HIVIAIDS. From the developed model, it be seen that HROL is related to health services, patient factors, family factors and empowerment.

Keywords: Belief, Family empowerment, Health-related quality of life, HIV/AIDS, Housewives

Correspondence:

Nursalam Nursalam

Faculty of Nursing, Universitas Airlangga, Surabaya, Indonesia

E-mail: nursalam@fkp.unair.ac.id

DOI: $10.31838 /$ srp.2020.5.37 @Advanced Scientific Research. All rights reserved

\section{INTRODUCTION}

The trend of HIV/AIDS prevalence in Indonesia shows significant increment (DG of Disease Control and Environmental $\mathrm{Health}$ and Ministry of $\mathrm{Health}$, Republic of Indonesia, 2014). In 2002, there was a new phenomenon of the HIV/AIDS spread in households ( $M$ inistry of $\mathrm{H}$ ealth, Republic of Indonesia, 2017). In addition, one of the problems in dealing with HIV-related symptoms over a long period are , social problems, stigma, poverty, depression, substance abuse and cultural beliefs, all of which have an effect on decreasing immunity $(1,2)$ and impact on quality of life in the form of $\mathrm{H}$ ealth Related Quality of Life (HRQL) $(3,4)$. Low HRQL can affect the immune response and make health conditions worsen $(5,6)$.

Quality of life is an individual's perception in life, cultural context, value system of life with goals, standard expectations and interest. HRQL assessment is a subjective evaluation that is embedded in the cultural, social and environmental context. Family Empowerment is a intervention to improve the HRQL of HIV/AIDS sufferers by involving the closest people in a sufferer's life, including family $(7,8)$. Empowerment increases the ability and independence of the community in improving living standards (9). H owever, the influence of belief-based family empowerment on $H Q R L$, community stigma and immune response (CD 4 and V iral Load) has not been proven.

There is a prevalence of more than 6.5 million women in Indonesia vulnerable to contracting with HIV, because infection cases appear in the household environment. Housewives with HIV/AIDS in 2017 reached the highest number of cases (12,302 housewives' infection) (Directorate General of Disease Prevention and Control, 2017). East Java, one of the areas with the greatest number of residents in
Indonesia, reported HIV / AIDS infection reached 362 cases. The increasing cases create a problem in HQRL due to welfare aspects and assessing the needs of patients used as material for health promotion.

Factors affecting HQRL are depression symptoms, physical functioning, overall general health and overall quality of life $(10,11)$. Referring to the change and maintenance of healthrelated behaviors, a guiding framework of health behavioral interventions is called the Health Belief Model (HBM) (12). $\mathrm{HBM}$ is a psychological theory predicting the emergence of a person's health behavior (13) and belief-based family empowerment has an impact on strengthening and improving the condition of HIV / AIDS sufferers. Reviewing using HBM can increase confidence and lead to improved HQRL in housewives infected with HIV/AIDS and is assessed through the body's immune response. This study aimed to develop a family empowerment model based on belief and analyze the effects of HRQL in patients infected by HIV/AIDS

\section{METHODS}

A mixed method study with the first stage of quantitative research design with cross - sectional approach was carried out. The study sample were 135 respondents using purposive sampling selection with inclusion criteria: women had been married; diagnosed with HIV/AIDS for at least six months; age above 20 years; and do not have psychiatric disorders. The exclusion criteria were hospitalized patients and patients in the severe category. For developing the model, we conducted the family empowerment interview instrument adopted from the family empowerment scale (FES) about quality of life and psychological fulfillment. We tested the validity of the results of the interview using a 
credibility test (internal validity) with triangulation of sources from patients, families, AIDS Commissions, and medical teams focusing on HIV/AIDS patients, and analyzed used grouping of themes, sub-themes and categories. The results were summarized and then validated again. Focus group and expert discussion were conducted after collecting data to make the model and intervention tool for stage two of the research. A nalysis between variables used Structural Equation Model - Partial Least Squares (SEM - PLS) T measure factors to develop the model.

\section{RESULTS}

M ajority of respondents aged 38-42 years (41/135, 30.4\%) and females were predominant $(73 / 125,54.1 \%)$. The most recent education respondents were high school graduates $(69 / 135,51.1 \%)$ and most respondents were married $(73 / 135,54.1 \%)$ with the average occupation being employee $(73 / 135,54.1 \%)$. From the study result, most of the HIV respondents were asymptomatic (65/135, 48.1\%) and no opportunistic infection (130/135, 96.3\%). Patient's conditions were independence $(123 / 135,91.1 \%)$ with feelings about health, both of condition and self-perception (113/135, 83.7\% and 104/135, 77.0\%, respectively). Some of respondents had been diagnosed HIV more than one year, first HIV test more than one monthsand had transmission from sexual activity (85/135, 63.0\%; 94/135, 69.6\%; 114/135, $84.4 \%$, respectively) (Table 1 )

Table 1: Characteristic of Respondents

\begin{tabular}{|c|c|c|c|}
\hline Characteristic of respondents & Parameter & $\mathbf{n}$ & $\%$ \\
\hline \multirow[t]{8}{*}{ Age } & $10-16$ & 1 & 0.7 \\
\hline & $17-23$ & 9 & 6.7 \\
\hline & $24-30$ & 20 & 14.8 \\
\hline & $31-37$ & 35 & 25.9 \\
\hline & $38-42$ & 41 & 30.4 \\
\hline & $43-50$ & 24 & 17.8 \\
\hline & $51-57$ & 4 & 3.0 \\
\hline & $58-64$ & 1 & 07 \\
\hline \multirow[t]{2}{*}{ Gender } & Male & 62 & 45.9 \\
\hline & Female & 73 & 54.1 \\
\hline \multirow[t]{4}{*}{ Education } & Elementary School & 27 & 20.0 \\
\hline & Junior High School & 26 & 19.3 \\
\hline & Senior High School & 69 & 51.1 \\
\hline & Bachelor & 13 & 9.6 \\
\hline \multirow[t]{4}{*}{ M arital Status } & Single & 36 & 26.7 \\
\hline & Married & 73 & 54.1 \\
\hline & Death divorced & 18 & 13.3 \\
\hline & Divorced & 8 & 5.9 \\
\hline \multirow[t]{4}{*}{ Job } & Civil servant & 2 & 1.5 \\
\hline & Employee & 73 & 54.1 \\
\hline & Enterpreneur & 21 & 15.6 \\
\hline & Doesn't work & 39 & 28.9 \\
\hline \multirow[t]{3}{*}{ HIV status } & Asymptomatic & 65 & 48.1 \\
\hline & Symptomatic & 49 & 36.3 \\
\hline & AIDS & 21 & 15.6 \\
\hline \multirow[t]{2}{*}{ Opportunistic infection } & Yes & 5 & 3.7 \\
\hline & No & 130 & 96.3 \\
\hline \multirow[t]{3}{*}{ Patient independence } & Independence & 123 & 91.1 \\
\hline & Partial care & 12 & 8.9 \\
\hline & Total care & 0 & 0 \\
\hline \multirow[t]{3}{*}{ Health condition } & H ealth & 113 & 83.7 \\
\hline & Unwell & 19 & 14.1 \\
\hline & Sick & 3 & 2.2 \\
\hline \multirow[t]{2}{*}{ Self Perception } & Being sick & 31 & 23.0 \\
\hline & Health & 104 & 77.0 \\
\hline \multirow[t]{2}{*}{ HIV diagnosed } & $<1$ Year & 50 & 37.0 \\
\hline & $>1$ Year & 85 & 63.0 \\
\hline
\end{tabular}




\begin{tabular}{llll}
\hline First HIV test & $<1$ M onth & 41 & 30.4 \\
\hline & $>1$ M onth & 94 & 69.6 \\
\hline HIV Transmission & Sexual fluid & 114 & 84.4 \\
\hline & IDU & 19 & 14.1 \\
\hline MTCT & 2 & 1.5 \\
\hline
\end{tabular}

\section{Variable Identification of Model Development}

Support from facility (59/135, 43.7\%), policy implementation (74/135, 54.8\%), HIV prevention (71/135, $52.6 \%)$ and government activity (40/135, 29.6\%) were subobservational variables for policy. Health services were measured by twovariables (health facility access and health workers) and both variables gave support to patient (64/135, 47.4\% and 107/135, 79.3\%) (Table 2). In addition, patient factors consisted of 13 variables: age, gender, education, marital status, occupation, HIV status, opportunistic infections, patient independence, health conditions, self-perception, duration of HIV infection, first HIV test and HIV transmission (Table 1).

Family burden, social support, family stress, and family resilience were observational variables for family factors. From the results, the predominant category was they were not supported to respondents with HIV (family burden, social support, family stress, $101 / 135,74.8 \% ; 58 / 135,43.0 \%$, $111 / 135,82.2 \%$, respectively), but there was family resilience support to patients $(83 / 135,61.5 \%)$. The empowerment of respondents was measured from cognitive, personal threat and motivation. The majority results in the criteria of empowerment were cognitive and personal threat (113/135, $83.7 \%$ and $108 / 135,80.0 \%$, respectively) and motivation as the most dominant indicator (124/135, 91.9\%) (Table 2).

HQRL was measured with physical function and overall general health. Of the three HQRL indicators, the majority of respondents felt quality of life in high condition. But there were some respondents who felt in a low condition after suffering from HIV. Respondents still needed efforts to strengthen $H Q R L$, especially in the aspects of physical function and overall general health, where there were still respondents in the low category $(102 / 135,75.6 \%$ and 92/135, 68.1, respectively) (Table 2).

Table 2: V ariable Identification of M odel Development

\begin{tabular}{|c|c|c|c|c|c|c|}
\hline \multirow{3}{*}{ Indicator } & \multicolumn{6}{|c|}{ Category } \\
\hline & \multicolumn{2}{|c|}{ Support } & \multicolumn{2}{|c|}{ Less Support } & \multicolumn{2}{|c|}{ Does not Support } \\
\hline & $\mathbf{N}$ & $\%$ & $\mathbf{N}$ & $\%$ & $\mathbf{N}$ & $\%$ \\
\hline \multicolumn{7}{|l|}{ Policy } \\
\hline Facility & 59 & 43.7 & 43 & 31.9 & 33 & 24.4 \\
\hline Policy Implementation & 74 & 54.8 & 37 & 27.4 & 24 & 17.8 \\
\hline HIV Prevention & 71 & 52.6 & 46 & 34.1 & 18 & 13.3 \\
\hline Government Activity & 40 & 29.6 & 27 & 20.0 & 68 & 50.4 \\
\hline \multicolumn{7}{|l|}{ H ealth service } \\
\hline H ealth facility access & 64 & 47.4 & 43 & 31.9 & 28 & 20.7 \\
\hline H ealth workers & 107 & 79.3 & 14 & 10.4 & 14 & 10.4 \\
\hline \multicolumn{7}{|l|}{ Family factors } \\
\hline Family burden & 8 & 5.9 & 26 & 19.3 & 101 & 74.8 \\
\hline Social support & 10 & 7.4 & 67 & 49.6 & 58 & 43.0 \\
\hline Family stress & 6 & 4.4 & 18 & 13.3 & 111 & 82.2 \\
\hline Family Resilience & 83 & 61.5 & 32 & 23.7 & 20 & 14.8 \\
\hline \multicolumn{7}{|l|}{ Empowerment } \\
\hline Cognitive & 113 & 83.7 & 17 & 12.6 & 5 & 3.7 \\
\hline Personal threat & 108 & 80.0 & 20 & 14.8 & 7 & 5.2 \\
\hline Motivation & 124 & 91.9 & 6 & 4.4 & 5 & 3.7 \\
\hline \multicolumn{7}{|l|}{ HRQL } \\
\hline Physical function & 92 & 68.1 & 32 & 23.7 & 11 & 8.1 \\
\hline Overall general health & 126 & 93.3 & 8 & 5.9 & 1 & 0.7 \\
\hline
\end{tabular}

\section{Evaluation of the 0 uter Model Analysis}

The outer model was evaluated by measurement of the validity and reliability. Convergent validity was determined using loading factors and the average variance value extracted (AVE). Measurements can be categorized as having convergent validity and reliability if the loading factor value $>0.6$ and $A V E$ value $>0.5$. Based on the research results, it can be seen that nine indicators were invalid (outer loading value was $\leq 0.4$ ), and these must be removed from the model. 


\section{Evaluation of the Inner Model Analysis}

Evaluation of inner models was used to test the research hypotheses. The research hypothesis can be accepted if the value of $T$ count $>T$ table. The health services, patient factors, family factors have a significant influence on empowerment ( $T$ >1.96). The results of the hypothesis test are described as follows: (1) Policies (facilities, policy implementation and government activities) improve empowerment; (2) Good health services (health workers) increase family empowerment; (3) Patient factors (age, marital status, patient independence, health conditions, selfperception, duration of HIV infection, first HIV testing, HIV transmission) influence empowerment; (4) Family factors (social support and family resilience) influence empowerment; (5) Empowerment (cognitive, personal threat, motivation) influences stigma (labeling, isolation, and discrimination); and Empowerment (cognitive, personal threat, motivation) affects HQRL (physical function and overall general health) (Table 3 ).

The evaluation of developing the family empowerment model based on belief with health-related quality of life was influenced by some factors: policy, health service, patient factors and family factors. Four latent variables impacted family empowerment and influenced HRQL. The novelty of this model was family empowerment based on belief; there were some components of the belief that were compared with empowering (Table 3).

Table 3. H ypotheses Test of M odel Development

\begin{tabular}{lllll}
\hline Varible & $\begin{array}{l}\text { Path } \\
\text { coeficient }\end{array}$ & $\begin{array}{l}\text { Std } \\
\text { Devition }\end{array}$ & $\begin{array}{l}\text { T } \\
\text { statistic }\end{array}$ & Significancy \\
\hline Effect policies to HQRL & .058 & .051 & .615 & Not significant \\
\hline Effect health service to HQRL & .379 & .150 & 1.847 & Significant \\
\hline Effect patient factors to HQRL & .173 & .243 & 3.343 & Significant \\
\hline Effect family factors to HQRL & .042 & -.414 & -5.258 & Significant \\
\hline Effect empowerment to HQRL & .084 & .473 & 6.383 & Significant \\
\hline
\end{tabular}

\section{DISCUSSION}

Family empowerment is important for people with HIV/AIDS in their life. Family with empowerment integrate in social processes, recognize, promote and enhance the ability of people to find their own needs, solve their own problems and mobilize the resources needed to control their lives (Arief et al., 2018). Family empowerment has the following components of patient participation, patient knowledge and patient skills (W ilson et al., 2018), which can be useful in the care of patients infected with HIV/AIDS. The importance of family participation in the model of empowerment developed is needed by HIV/AIDS fighters; the support system of the family can increase patient motivation to improve body immunity and health (5)

Family empowerment combines with HBM , a psychological theory focused on health behavioral changes, giving effect to strengthen and change the HIV/AIDS condition based on belief so as to improve HRQL in housewives. In this research, we focused on developing a model of family empowerment based on belief; empowering was main component to increase motivation in HIV/AIDS sufferers. Empowering can make a person more confident and believe in fighting HIV/AIDS, even though the immune system may be worsening. HRQL is related to health services, patient factors, family factors and empowerment in patients with HIV. HRQL is a multi-dimensional concept that includes domains related to physical, mental, emotional, and social functioning (5). It goes beyond direct measures of population health, life expectancy, and causes of death, and focuses on the impact health status has on quality of life (4). We found in our study that health service variables (health facility access and health worker) were reported supporting to HRQL.

Improved health services for HIV/AIDS patients are needed to make sufferers healthier, more qualified and productive, so that they do not fall into the condition of AIDS and bring about many symptoms (14). H ealth services for people with HIV/AIDS must be provided early, especially when a patient's diagnosis is established (15). Patients will feel quality of life if the disease is at the stage of acceptance (16). Health workers are also associated with HRQL patients because they give the best service when patients go to healthcare services for medicine regularly (17).

Patients factors showed significant association to HRQL; based on this research, productive age, 38-42 years, has effect on HRQL (9). In contrast with the result of chronic disease quality of life, no significant correlations were found between age of the assessed HRQL domains or symptom scales, but the results are in line with research about older age feeling about end of life (18). They stated that age has association with quality of life, because age gives them experience to face their problems and activities during life. Females also associate with good HRQL, the reason being many women become housewives and they will accept faster than career women (5). M ales with HIV/AIDS showed worse quality of life because it changes their role in family. Education and marital status have better HRQL because higher education background makes sufferer better understand and being in relationship as a couple can give them support while suffering HIV/AIDS (1). Acceptance period in HIV/AIDS patients showed variation; some sufferer just needed less than one year and others need more to accept with their condition. HIV/AIDS transmission has become the highest cause to psychological responses in patients (4).

The role of the family has high contribution to quality of life in HIV/AIDS patients. Family burden, social support, family stress and family resilience show different ways in every family. When a family cares for HIV/AIDS patients, they generally state that they feel a burden and get tired because patients are often readmitted to the hospital. This condition 
make them spend their time in the hospital to support their families member (19). Supporting factors also give good contribution in HIV/AIDS quality of life, because better HRQL was show from respondents who had good support from their family, friends and society (20). Family burden in caring of HIV/AIDS patients causes stressors in family and can develop to psychological stress. Some of the family will feel burnout and give up. From this condition, family resilience becomes an important factor (21). Family resilience showed better results when the relation between family members was good. The empowerment of patients will increase patient activity and actualization, allowing the patient to develop their ability and not limit their actions. HIV sufferers can give each other support and work together. Some of the sufferers join the HIV/AIDS community and there are many events or activities to build their confidence and support each other $(15,17,19)$.

\section{CONCLUSION}

The development of the family empowerment model based on belief has a good effect in quality of life among housewives with HIV/AIDS. The model gives new advantages to improve motivation and belief in HIV/AIDS sufferers. This model development goal was empowerment of the family role to give care to sufferers and this has good impact on patients HRQL. The evaluation of the family empowerment model based on belief in regard to healthrelated quality of life was influenced by some factors: influenced were policy, health service, patient factors and family factors.

\section{REFERENCES}

1. Huang W, O perario D, Dong $Y$, Zaller $N$, Song $D, H e$ $\mathrm{H}$, et al. HIV-Related Risk Among Female M igrants W orking in Entertainment V enues in China. Prev Sci. 2014;15(3):329-39.

2. Maixenchs $M$, Boene $H, A$ nselmo $R, M$ indu $C$, A lonso $P$, Menéndez $C$, et al. Post-ART symptoms were not the problem: A qualitative study on adherence to ART in HIV-infected patients in a mozambican rural hospital. PLoS One. 2015;10(9).

3. Garrido-Hernansaiz H, Heylen E, Bharat $S$, Ramakrishna J, Ekstrand ML. Stigmas, symptom severity and perceived social support predict quality of life for PLHIV in urban Indian context. Health Qual Life O utcomes. 2016;14(1).

4. George S, Bergin C, Clarke S, Courtney G, Codd M B. $\mathrm{H}$ ealth-related quality of life and associated factors in people with HIV: An Irish cohort study. Health Qual Life O utcomes. 2016;14(1).

5. M iners A, Phillips A, Kreif N, Rodger A, Speakman A, Fisher $M$, et al. Health-related quality-of-life of people with HIV in the era of combination antiretroviral treatment: A cross-sectional comparison with the general population. Lancet HIV . 2014;1(1):e32-40.

6. Pancera M, Zhou T, Druz A, Georgiev IS, Soto C, Gorman J, et al. Structure and immune recognition of trimeric prefusion HIV-1 Env. Nature. 2014;514(7253):455-61.

7. Maclachlan EW, Potter K, Hamunime N, Shepard-
Perry MG, Uusiku J, Simwanza R, et al. "We are now free to speak": Qualitative evaluation of an education and empowerment training for HIV patients in N amibia. PLoS O ne. 2016;11(4).

8. Fiscella K, Boyd M, Brown J, Carroll J, Cassells A, Corales R, et al. Activation of persons living with HIV for treatment, the great study Health behavior, health promotion and society. BMC Public Health. 2015;15(1).

9. M acLachlan EW, Shepard-Perry M G, Ingo P, U usiku J, Mushimba R, Simwanza R, et al. Evaluating the effectiveness of patient education and empowerment to improve patient-provider interactions in antiretroviral therapy clinics in Namibia. AIDS Care Psychol Socio-Medical Asp AIDS/HIV. 2016;28(5):620-7.

10. Yohannes AM, Alexopoulos GS. Depression and anxiety in patients with COPD. Vol. 23, European Respiratory Review. 2014. p. 345-9.

11. Nanni MG, Caruso R, Mitchell AJ, Meggiolaro E, Grassi L. Depression in HIV Infected Patients: A Review. Vol. 17, Current Psychiatry Reports. 2015. p. 1-11.

12. Abraham C, Sheeran P. The health belief model. In: Cambridge Handbook of Psychology, Health and M edicine, Second Edition. 2014. p. 97-102.

13. Jones CJ, Smith $H$, Llewellyn C. Evaluating the effectiveness of health belief model interventions in improving adherence: a systematic review. Health Psychol Rev. 2014;8(3):253-69.

14. Cooper V, Clatworthy J, Harding R, Whetham J, Brown $A$, Leon $A$, et al. Measuring quality of life among people living with HIV : A systematic review of reviews. Vol. 15, Health and Q uality of Life Outcomes. 2017.

15. Bhatta DN, Liabsuetrakul T, McN eil EB. Social and behavioral interventions for improving quality of life of HIV infected people receiving antiretroviral therapy: A systematic review and meta-analysis. Health and Quality of Life O utcomes. 2017.

16. M wesiga EK, Mugenyi L, Nakasujja N, Moore S, Kaddumukasa M, Sajatovic M. Depression with pain co morbidity effect on quality of life among HIV positive patients in U ganda: A cross sectional study. Health Qual Life Outcomes. 2015;

17. M wai GW, M buru G, Torpey K, Frost P, Ford N, Seeley J. Role and outcomes of community health workers in HIV care in sub-Saharan Africa: A systematic review. $V$ ol. 16, Journal of the International AIDS Society. 2013.

18. Oguntibeju 00. Quality of life of people living with HIV and AIDS and antiretroviral therapy. HIV/AIDS - Research and Palliative Care. 2012.

19. Lee $\mathrm{S}$, Yamazaki M, H arris DR, Harper GW, Ellen J. Social support and human immunodeficiency virusstatus disclosure to friends and family: Implications for human immunodeficiency virus-positive youth. J A dolesc Heal. 2015;57(1):73-80.

20. Amiya RM, Poudel KC, Poudel-Tandukar K, Pandey $B D$, Jimba M. Perceived family support, depression, 
and suicidal ideation among people living with HIV/AIDS: A cross-sectional study in the Kathmandu Valley, Nepal. PLoS One. 2014;9(3).

21. WHO. Service Availability and Readiness Assessment (SARA): An annual monitoring system for service delivery - Reference M anual, V ersion 2.2. Heal Stat Inf
Syst [Internet]. 2015;175. Available from: https://apps.who.int/iris/bitstream/handle/10665/1490 25/WHO_HIS_HSI_2014.5_eng.pdf 